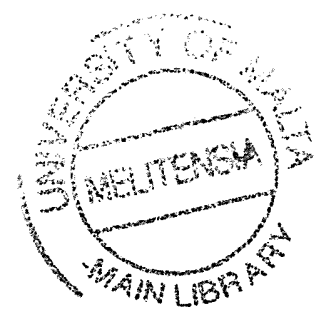

\title{
Languages and Varieties in Use in Malta Today: Maltese, English, Italian, Maltese English and Maltaliano
}

\author{
Joseph M. Brincat
}

Persons who have never visited Malta usually fail to realize that Maltese 'works' as a normal language. This is because most islands in the Mediterranean speak a dialect or a local variety of the language spoken in the nearest large nation state: in Majorca and Minorca they speak Spanish, in Corsica some speak the patois but most speak only French, their official language, in Pantelleria they speak Sicilian and write Italian, in Jerba they speak Arabic, in Crete Greek and in Cyprus Greek or Turkish. The 400,000 inhabitants of Malta and Gozo, living in an area of just $316 \mathrm{sq} \mathrm{km}$, nowadays use Maltese, English and Italian regularly, and their exposure to these three languages unavoidably determines a degree of intermingling. Because of its situation at the centre of the Mediterranean, Malta is not only exposed to the four winds and to strong sea currents, it is also swept by the prevailing cultural trends, today as in the past. The use of three languages in Malta is attested as far back as the early Roman period (from 2 I 8 to the first century BC), by inscriptions in Punic, Greek and Latin, and again during the post-Norman period, when documents were written in Latin and/or chancery Sicilian, while Mạttese continued to be spoken. ${ }^{\mathrm{I}}$ This is the only variety of Maghreb Arabic that survived from the Muslim expansion into Spain and Sicily, where it died out in the fifteenth and the thirteenth centuries respectively, while Pantelleria kept it at least up to the seventeenth century. ${ }^{2}$ ) During the time of the Order of St John, Malta was multilingual, thanks to the presence of hundreds of French, Spanish, Portuguese, Italian, German and English knights, sailors, soldiers and servants. The local population, however, used only Latin, Italian (which replaced Sicilian in local documents and Maltese, which was also studied and written, with the result that grammars, dictionaries, poems and sermons were produced in manuscripts as well as in print.

English was introduced to the island only in I800, when Napoleon was ousted and his plans for a Frenchified Malta were shelved, but it did not spread quickly. In fact anglicization was strongly resisted by the local inhabitants, who stuck to their Roman Catholic religion, their Italian culture and legal system, and their Semitic tongue, The British felt uncomfortable governing an island in Italian. All official communications 
had to be translated into Italian, and official publications and notices were bilingual. Consequently, the process of Anglo-Italian interference started, and continues to this day. Very few locals learned English during the nineteenth century, but, after a slow start, English overtook Italian in I9II, when I3.I per cent of the population declared that they could read, write or speak it, against II.5 per cent who knew Italian. Obviously, literacy was low in those days, and the figures overlap because most educated people learned both languages. The British pressed the issue of anglicization only after the Unification of Italy, when their (unjustified) apprehension over the strength of this new, large nation urged them to build new forts all over the island, since they feared that Italy, by conquering Malta, could cut off access to the recently built Suez Canal. Knowing that the educated Maltese considered Italy to be their cultural and spiritual parent, the British strove to offset this loyalty by gaining support among the inhabitants, and so they sent over Patrick Keenan, an Irish educationalist, to reform the local schools system. ${ }^{4}$ By I93I the number of persons knowing English was almost double that of those who knew Italian, because the British stepped up their efforts when the fascists seized power in Italy and war loomed ahead. ${ }^{5}$ Maltese, which had been promoted by the locals as a literary medium throughout the nineteenth century, was officially recognized in 1934, and Italian was dropped in 1936. Public notices, street names and Christian names were changed, English became compulsory for employment in the Armed Forces and the Civil Service, and the Second World War dealt a decisive blow to the prestige Italian enjoyed before I939. Ironically, anglicization spread after the war, even though it was no longer in the British government's interest to pursue it. Maltese society changed drastically in the post-war period: compulsory education was introduced in 1946, the cinema became the most popular form of entertainment, pop music was all the rage on radio stations, and English came to be associated with all things modern, including the way of life. Italian regained popularity in the late Fifties, when television was introduced in Sicily and Italian channels could be followed in Malta, mending the image created by prewar propaganda. In 1964 a domestic station started broadcasting locally produced programmes in Maltese and imported ones in English, but Italian channels continued to attract the greater part of the audience up to $1996,{ }^{6}$ when the major political parties set up their own stations. The introduction of satellite and cable television brought Italian viewership down to about 20 per cent.

These are the facts, seen in their historical perspective, that have made the Maltese people skilful at mixing languages. I must stress that this is not simply a case of individuals learning a new language, although I expect a number of the strategies to be somewhat similar, but that of a community having been exposed to different languages over a very long period. In fact the last census, held in I995, shows that out of a total population of 324,386 aged sixteen and above, 3I7,3II were Maltese speakers, 246, I57 had learnt English well, and II 8,2 I3 knew Italian, while languages studied only as school subjects followed at a certain distance: French (3I,945), German (6807), Arabic (5955) and Spanish (1955). The immediate result of this strong exposure and widespread use of different languages is the ongoing change of the native language. Under the cumulative effect of nine hundred years of contact, not only with foreign rulers and their retinue but even more importantly with immigrants at the lower social levels, the stratification of the 
Maltese language evolved rapidly and substantially. Its lower and oldest layer, though still perceived as the main stratum (the one that proves its Semitic origins), provides only $32.4 \mathrm{I}$ per cent of the lexemes in Joseph Aquilina's Maltese-English Dictionary. ${ }^{7}$ The Romance element, mostly from Sicilian and Italian, ${ }^{8}$ has risen to 52.46 per cent, while the English element makes up 6.12 per cent of the total of $4 \mathrm{I}, 000$ lexemes. ${ }^{9}$ As a result, words of non-Semitic origin form no less than 60.23 per cent of the lexicon, although the quantitative factor is offset by frequency. In fact Semitic terms prevail in any text, because function words are repeated many times and basic words are used more often than specific terms. However, the lexical composition of texts varies greatly according to register (poetic, prose, journalistic, spoken) or domain (religious, administrative, legal, technical, scientific, rural, domestic, etc.). On the whole, the word count gives an idea of how the language has grown in the past 900 years in order to keep pace with the social and cultural development of the community that speaks it. Although the basic Semitic lexical core satisfies the communicative needs of a rural society and of most personal and domestic situations, ${ }^{10}$ the vocabulary acquired over the centuries kept growing as new skills were assimilated. In this respect, Sicilian words can be seen to abound in traditional crafts like woodwork, fishing, building, and so on, while Italian words are mostly used in the spheres of education, culture, religion, administration and the law. In addition, the particular terminology of new areas and activities introduced during the British period - the dockyards, aviation, accountancy and taxation - or of those fields that have undergone drastic renewal, such as medicine, the sciences and technology, especially those involving electrical and electronic appliances and practices, is replete with English words.

The number of Romance terms is easily accounted for by the long period of their use in administration and culture, but the English lexical component would seem to be too low, considering that the British ruled Malta for almost 180 years and that their contacts were not restricted to the nerve centres of government but spread out from garrisons in. which thousands of troops were stationed, as well as from the homes of a sizeable number of servicemen's families. The Armed Forces were also the main source of local employment. Aquilina's inclusion of 2500 words is surprisingly close to the number of English words in the vocabulary of Italian, as shown in studies by Klajn, Rando, and Carpitano and Casole; ${ }^{\text {II }}$ but with regard to the knowledge and use of English, there is absolutely no comparison between Malta and Italy, where English is simply a foreign language, though nowadays increasingly studied at school. After Gibraltar, Malta was the first country in Europe to adopt English in its school system, and since 1946 it is not only compulsory but also the main medium of instruction in most subjects, from kindergarten to university. In the May 2003 examination session, no less than 5623 students sat their $\mathrm{SEC}^{\mathrm{I} 2}$ in English, 4943 took Maltese, and 3027 Italian. Besides, English is the preferred language for reading: in 2001 the importation of books and newspapers in English stood at 4,665,623 Maltese liras (almost three million sterling), followed by those in Italian, worth just over half a million ML (£,305,000); and books borrowed from national and local libraries are almost exclusively in English. All local cinemas show English-language films, and over 60 per cent of tourists are British, which helps to keep up the pre-Independence opportunities for locals to practise their English conversation: 
One unfortunate result of this exposure to English is language switching. Fifty years ago very little of it occurred: everybody spoke Maltese, and English was used only in formal class situations at school or else informally to English teachers, of whom there were quite a number, especially in secondary schools, training colleges and at university. When I went to university, at the time the Beatles burst upon the scene, it became fashionable for girls to speak English, the boys reluctantly following suit when socializing with them - without much success, since more girls' than boys' schools enforced the total immersion system. Later on, it became fashionable for young mothers to speak to their children in English, with varying degrees of success, depending on personal competence. Surveys of what takes place in schools reveal an alarming situation. ${ }^{\mathrm{I} 3}$ In order to ensure bilingualism official policy decrees that most subjects, such as English, maths, the sciences, accounts, etc., must be taught through English, but language switching is rife in certain schools, especially in classes made up of underachievers. The normal pattern is to use the terminology in the textbooks, which is English, but with the sentence strung together in Maltese, as the following examples illustrate: ${ }^{14}$

\section{At school:}

Mathematics lesson: $i d$-diameter, le, mhux ir-radius

[the diameter, no, not the radius]

Biology lesson: l-istructure tal-leaf [the structure of the leaf]

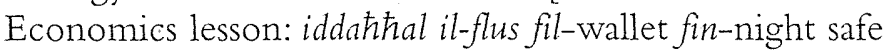

[you put the money in the wallet in the night safe]

At home:

Gibli n-napkin minn fuq id-dishwasher

[get me the napkin which is on the dishwasher]

Tih il-bottle lill-baby [give the bottle to the baby]

In the office:

Il-mag்goranza tat-taxpayers ma jkollomx bżonn jimlew ir-return ta' l-income tax

[the majority of the taxpayers do not need to fill in the income tax return]

Such conversation between pupils and teachers resembles that between mothers and children, and seems to be carried on into the working environment, especially offices and laboratories, where new methods bring in frequent changes of terminology. Everyone condemns this kind of intermingling, but under certain circumstances at least one third of the population resort to it. ${ }^{\text {IS }}$ It cannot be defined as 'pidgin' or 'creole', because it is not considered as anyone's native language. People attach little importance to it, and tend to dismiss it as an informal slip. A colleague of mine believes it to be the result of 'mental sloth', but I dare to suggest that it may be defined as a form of semi-conscious interlingua, a kind of shifting stage between the use of two languages. Its main characteristic is that speakers are very much aware that Maltese and English are separate languages, because they resort to language switching only when conversing with persons who know both languages. Nobody switches when speaking to Maltese monolinguals or to English people or foreigners. It is carefully avoided when writing, because then one has time to reflect and choose the right word. It is therefore a kind of compromise between bilinguals, a means of speeding up an informal conversation, especially when one knows that a technical 
term is more frequently used in a particular environment. This does not mean that English loanwords are not written down, but their use is limited to cases where a Maltese equivalent is lacking. Obviously, no one uses Maltese words when writing in English, unless a word has a special connotation that is untranslatable, in which case a periphrasis would usually be adopted.

As to the question of why so few English words have been included in Aquilina's dictionary in spite of the widespread use of English in Malta, the reason is that a good number of English words are camouflaged. Whenever possible, English expressions are translated literally and are no longer perceived as English at all. A common example is the passive construction 'It is understood that ...', which is unnatural in Maltese syntax but is heard in most news bulletins as 'Jiği mifhum li .... This represents the opposite situation in Maltese English, when native speakers translate Maltese expressions into English words, uttering phrases such as 'I'm going to cut, now' (on the phone) for 'I'm going to hang up', 'I'm going to buy' for 'I'm going shopping', or 'I'll pay you a drink' instead of 'I'll buy you a drink'. ${ }^{16}$ Sometimes phonetic changes happen, as in the initial vowel of olternattiva, influenced by the first syllable of the English pronunciation of 'alternative', and restorant from the first syllable of 'restaurant', replacing the local forms alternattiva and ristorant adapted from the Italian alternativa and ristorante.

When English words are used in an unmodified form, the writer becomes aware that the two spelling systems are widely different. There are two opposite schools of thought here: some people, especially those who are very patriotic, decree that English words should be written according to the Maltese system, which makes them strictly phonetic, almost like the IPA. In this way 'bicycle', 'baby' and 'night shift' are written bajsikil, bejbi and najt xift. However, since everybody in Malta has learnt how to read English, such spelling renders the words unrecognizable, and the effort to decipher their appearance is often considered time-wasting and useless. On the other hand, one may object that the intricacies of English spelling do not always allow a word's correct pronunciation to be rendered clearly without the use of diacritical signs. An apparently simple word like 'pretty', when written as priti, does not convey the accent and the length of the vowel, and a Maltese reader is tempted to read it like miti or siti. The latter are identical to the original Italian words miti and siti, plural forms of mito and sito, showing that Maltese spelling is much closer to Italian, of which it may be considered an even more phonetical version (see note I4 below). One may argue that many of the major languages treat English loanwords in this way; for example, this is the practice in Spanish, but then it should be kept in mind that the Spanish people as a whole do not use English at all, while in Malta everybody learns it from age six onwards, if not before.

Transcription of English words of Romance origin is much easier, even if requiring certain modification; certainly, this is the most intriguing aspect of linguistic interference in Malta. Although two thirds of the Maltese declare a knowledge of Italian (see the I995 census mentioned above), average competence does not extend beyond GCSE standard; and although Italian is considered very easy to learn, its everyday use is largely passive. Moreover, the presence of so many Italian words in the Maltese lexicon (almost 53 per cent ) may facilitate understanding, but semantic changes may also create difficulties. Italian is no longer the only source of lexical 
innovation, a role that has been taken over by English. And yet Maltese speakers have not lost the mechanical ability of effecting the phonetic transformation of Italian words into Sicilian patterns. This consists mainly of reducing the final vowels to three - $a, i, u$ - and changing $o>u$ and $e>i$ in certain contexts, as well as doubling some consonants, ${ }^{17}$ as the following examples show. The important thing to note is that these changes are automatically applied to English words of Latin and French origin. It is obviously easy to turn 'prosecutor' to prosekutur, 'industrial action' into azzjoni industrjali, and 'chemical armaments' into armamenti kemikali, three examples that clearly show that the Italian equivalents pubblico ministero, vertenza sindacale and armi chimiche are not familiar. However, certain adaptations require more complex operations, like finding a suffix for the derivation of nouns from verbs. The verb 'to assess' is conjugated according to the Arabic paradigms of Maltese but with special modifications for English verbs, as Mifsud has shown, ${ }^{\text {I8 }}$ while the Italian suffix of the infinitive -are is added to produce a new form, l-assessjar 'the assessing', which has an Italian appearance but obviously no Italian source. The process used is that of analogy, and therefore the English past participle suffix '-ed' is replaced by the Italian -ato, or -uto, as in 'affected' > affettwat and 'involved' > involut. Thus 'alleged' becomes allegat, while 'allegedly' becomes allegatament because the ending '-ly' is replaced by the Italian equivalent -mente $>$-ment. Adjectives ending in '-ive' become -iv in the singular and -ivi in the plural, by analogy with the Italian -ivo/ivi, as in 'prospective students' > studenti prospettivi.

Nouns ending in '-ation' are unproblematic, and so 'implementation' becomes implimentazzjoni and 'accomodation' akkomodazzjoni; but some cases defy interpretation: 'involvement' retains its suffix in involviment, but 'enforcement' does not, substituting -ar (-are) to produce l-infurzar. Other English nouns ending in '-ity', 'ency' and '-ude' are given the corresponding Italian suffixes, as in 'amenity' > ameniti, 'constituency' $>$ kostitwenza, and 'platitude' $>$ platitudni. These few examples show that some words are restored to their original Italian form, while orhers are simply invented. However, all keep their English meanings. Occasionally, some adaptations of English Latinate words may shock persons who know Italian well, like żviluppaturi for 'developers' (It. speculatori) and attentat, which translates 'attempt' (It. tentativo), and can produce paradoxical phrases such as il-gvernijiet ghamlu attentat biex igibu l-paci fir-regjun for 'the governments have made an attempt to bring peace to the region'. Most Maltese speakers are simply not aware that these forms either do not exist in Italian or carry-different meanings, and they tend to use them when speaking Italian. Students also tend to reproduce these interferences in their written work, a practice for which the term 'maltaliano' has been coined, suggesting both 'bad Italian' (male + italiano) and 'Maltese Atalian' (Malta + italiano); but perhaps Italian is not used enough nowadays to justify the existence of a Maltese variety.

Living with three languages does produce problems, but on the whole Maltese citizens succeed in communicating to meet their own particular needs, obviously in different degrees according to linguistic competence. A look at the future may be attempted here, but it is not easy to perceive a trend, since conditions nowadays are very different to those of the past. Maltese has survived for nine centuries as a spoken language in a state of diglossia, but up to the I950s the majority of the islands' 
inhabitants were monolingual. The language expanded as a result, thanks to the influx first of Sicilian, then of Italian words, which immigrants and the few literate Maltese passed on orally to the illiterate population in a very slow but steady process. Since the I950s, literacy figures have been inverted, with 90 per cent being able to read and write Maltese and English and only about Io per cent showing problems. However, even the latter enjoy daily exposure to English, for they have attended school for about ten years and must have picked up something; moreover, they always watch English films at the cinema or on television, and thousands of fans follow the Premier League or Campionato matches, or both, every weekend, not forgetting the midweek games for the European cups.

As mentioned above, about 30 per cent of bilinguals resort to language switching, which will certainly bring about an increase in the number of English words that are absorbed into the Maltese language. New problems may arise. Will the practice of switching ever reach the extremes evident in the variety spoken by Maltese migrants in Australia? ${ }^{\mathrm{I} 9}$ Will English words erode the core vocabulary? Or will vigilance in schools and general social awareness succeed in keeping the two codes separate? At present, Maltese is still spoken regularly by over 90 per cent of the island's inhabitants, most of whom consider English indispensable in today's world. Interest in Italian is still very much alive, but it is obviously no longer regarded as a threat to Maltese. The latter has strengthened its position by penetrating areas that a few decades ago were considered to be the domains of English, namely the written register and official use. Maltese is used regularly in parliament, the law courts, the church and all government offices. It is also recognized as one of the official languages of the European Union. The media offer two daily newspapers in Maltese, alongside two others in English, and no less than 27 local radio stations broadcast programmes in Maltese (compared with two in English), while six local television channels produce programmes in Maltese and relay imported programmes in English. Even ATMs and the Google search engine offer the option of interaction in Maltese. Official policy aims at achieving bilingualism with good competence in both languages. As far as one can tell, Maltese will survive, although (or because) it is changing, as long as its speakers still consider it important and efficient. The community's knowledge of English may even ensure the survival of the local language, since the use of English for international communication will ease the pressure for too rapid change and for the excessive growth of Maltese.

\section{Notes to Chapter I2}

I. Joseph Cremona, 'The Survival of Arabic in Malta: the Sicilian Centuries', in The Changing Voices of Europe: Papers in 'Honour of Professor Glanville Price, ed. by M. Mair Parry, Winifred V. Davies and Rosalind A.M. Temple (Cardiff: University of Wales Press, 1994), pp. 28I-94.

2. In the study quoted in n. I, Joseph Cremona mentions a French merchant who in 1670 declared that 'the same language is spoken in Malta and in Pantelleria' (p. 290, n. 7).

3. Giuseppe Brincat, 'L'italiano della Corona Britannica', in La lingua d'Italia. Usi pubblici e istituzionali. Atti del XXIX Congresso internazionale SLI, Malta, 3-5 novembre 1995, ed. by Gabriella Alfieri and Arnold Cassola (Roma: Bulzoni, I998), pp. 377-97.

4. Joseph M. Brincat, 'The Language Question and Education: a Political Controversy on a Linguistic Topic' in Yesterday's Schools: Readings in Maltese Educational History, ed. Ronald G. Sultana (Malta: PEG, 200I), pp. 137-58. 
5. Geoffrey Hull, The Malta Language Question: A Case Study in Cultural Imperialism (Malta: Said International, I993), pp. 50-93.

6. 'Languages across Frontiers: The Acquisition of Italian in Malta by Viewers of Italian TV Programmes', in Proceedings of the XVIth International Congress of Linguists/Actes du 16 Congrès international des linguistes, Paris, 20-25 July 1997, ed. by Bernard Caron (Oxford: Elsevier, 1999) [on CD-ROM].

7. Joseph Aquilina, Maltese-English Dictionary, 2 vols (Malta: Midsea Books, 1987-90). The same author also produced the English-Maltese Dictionary, 4 vols (Malta: Midsea Books, 1999-2000).

8. See Joseph Cremona, 'The Romance Element in Maltese: A Review of the Problems', Transactions of the Philological Society, 88 (1990), I63-99.

9. Joseph Brincat, 'Purism and Neologism in Contemporary Maltese', in Purism in Minor Languages, Endangered Languages, Regional Languages, Mixed Languages [Papers from the conference on 'Purism in the Age of Globalisation', Bremen, September 200r], ed. by Joseph Brincat, Winifred Boeder and Thomas Stolz (Bochum: Brockmeyer, 2003), pp. I55-70 (I62-63). See also Giuseppe Brincat, Malta. Una storia linguistica (Genoa: Le Mani, 2004), pp. $35 \mathrm{I}-66$, for a fuller treatment of lexical quantity and frequency. An English version of this linguistic history of Malta is in preparation.

Io. The literary register, which was traditionally identified with Maltese, could afford to be puristic only because it treated such time-honoured topics as idealized love, religious sentiment, patriotism, sketches of village life and love of nature.

II. Quoted in Anna Laura Lepschy and Giulio Lepschy, 'L'italiano visto dall'estero', Lettera dall'Italia, 5 (1990), $53-54$.

I2. Equivalent to GCSE (General Certificate of Secondary Education, formely 'O' level) in the UK.

13. Antoinette Camilleri, Bilingualism in Education: The Maltese Experience (Heidelberg: Julius Groot, 1995).

I4. The Maltese alphabet uses some letters with diacritical signs: a dot over $\mathrm{c}$ and $\mathrm{g}$ distinguishes the palatal sounds $(\dot{\mathrm{c}})(\dot{\mathrm{g}}),[\mathrm{t} f]\left[\mathrm{d}_{3}\right]$ from the velar plosives $(\mathrm{k})(\mathrm{g})$; a dot over $\mathrm{z}$ shows the voiced alveolar fricative $(\dot{z})[z]$ which is distinguished from voiceless $(s)[s]$; a barred $h(\hbar)$ is aspirate (voiceless pharyngeal fricative), while $(\mathrm{h})$ is mute, and so is the digraph (gh), both being used for etymological purposes representing lost sounds. A few letters do not correspond to English usage: (q) indicates the voiceless glottal plosive [?], (x) the voiceless palato-alveolar fricative [S] (Eng.sh), and (j) the palatal semiconsonant [j] (Eng. y).

I5. Lydia Sciriha and Mario Vassallo, Malta: A Linguistic Landscape (Malta: Socrates Office, University of Malta, 200I).

16. Gabriella Mazzon, L'inglese di Malta (Napoli: Liguori, I992).

17. Cremona, 'The Romance Element in Maltese', pp. 180-81.

18. Manwel Mifsud, Loan Verbs in Maltese: A Descriptive and Comparative Study (Leiden: E. J. Brill, I995), pp. $213-5$ I.

19. Roderick Bovingdon, The Maltese Language of Australia: Maltraljan (Munich: Lincom Europa, 200r). 